\section{Correlation between Muscle Glycogen Synthase Activity and In Vivo Insulin Action in Man}

\section{Bogardus, S. Lillioja, K. Stone, and D. Mott}

Phoenix Clinical Research Section, National Institute of Arthritis, Diabetes, Digestive and Kidney Diseases, National Institutes of Health, Phoenix, Arizona 85016 bstract. We have studied the relationship between in vivo insulin-mediated glucose disposal rates, muscle glycogen content, and muscle glycogen synthase activity in 25 southwest American Indians with normal glucose tolerance and with varying degrees of glucose intolerance. Insulin-mediated glucose disposal (M) was measured by using the hyperinsulinemic euglycemic clamp technique at plasma insulin concentrations of $134 \pm 7$ and $1709 \pm 72 \mu \mathrm{U} / \mathrm{ml}$, with simultaneous indirect calorimetry to assess glucose oxidation and storage rates. Muscle glycogen content and glycogen synthase activity were measured in percutaneous muscle biopsy samples obtained from the vastus lateralis muscle before and after the euglycemic clamp procedure. The results showed that muscle glycogen synthase activity at the end of the euglycemic clamp was well correlated with insulin-mediated glucose storage rates at both low $(r=0.50, P<0.02)$ and high $(r=0.78, P<0.0001)$ insulin concentrations; and also correlated with $\mathrm{M}(r=0.66, P<0.001$ and $r$ $=0.76, P<0.0001)$. Similar correlations were observed between the change in muscle glycogen synthase activity and glucose storage rates and $\mathbf{M}$. The change in muscle glycogen synthase activity correlated with the change in muscle glycogen content $(r=0.46, P<0.03)$ measured before and after the insulin infusions. The change in muscle glycogen content did not correlate with glucose storage rates or $\mathbf{M}$. The data suggest the possible importance of glycogen synthesis in muscle in determining in vivo insulin-mediated glucose disposal rates in man.

\section{Introduction}

Recent studies in man have shown that most of an oral or intravenous glucose load is taken up by muscle $(1,2)$. Fur-

Received for publication 28 September 1983 and in revised form 5 January 1984.

The Journal of Clinical Investigation, Inc.

Volume 73, April 1984, 1185-1190 thermore, insulin-mediated glucose disposal by muscle appears to be predominantly by nonoxidative pathways, presumably glycogen synthesis (1), and the rate-controlling enzyme in this process is glycogen synthase (3). We have previously reported (4) a good correlation between muscle glycogen synthase \%I activity (percent active independent of glucose-6-phosphate [G6-P]) $)^{1}$ and insulin-mediated glucose disposal rates in Caucasian males following glycogen-depleting exercise. This suggested that glycogen synthase activity may be an important determinant of in vivo insulin-mediated glucose disposal rates in glycogendepleted man.

To ascertain if muscle glycogen synthase activity may be a determinant of insulin-mediated glucose disposal rates in rested, glycogen-replete subjects, we have analyzed the relationship between muscle glycogen synthase activity and in vivo insulin action in a group of southwest American Indians. The relationships were examined over a broad range of insulin-mediated glucose disposal rates by studying subjects with normal glucose tolerance and varying degrees of glucose intolerance. The hyperinsulinemic euglycemic clamp technique was used to assess in vivo insulin action at a low and very high plasma insulin concentration. Simultaneous indirect calorimetry was used to estimate insulin-mediated glucose oxidation and storage rates. These measures of insulin action were then compared to the muscle glycogen content and glycogen synthase activity before and after the euglycemic clamp procedure.

\section{Methods}

Subjects. 25 southwest American Indians, 14 females and 11 males, were admitted to the clinical research ward for study. Their characteristics are shown in Table I. After written informed consent was obtained, all subjects were physically examined and a 12 lead electrocardiogram recorded. After an overnight fast, blood was drawn for complete blood count, liver function tests, blood-urea nitrogen, creatinine, electrolytes,

1. Abbreviations used in this paper: ffm, fat-free mass; G-6-P, glucose6-phosphate; GSLo, glycogen synthase activity measured at a low G-6-P $(0.17 \mathrm{mM})$ concentration; \%GSLo, glycogen synthase activity measured at a low G-6-P concentration relative to the activity in the presence of high G-6-P; \% I activity, percent glycogen synthase activity independent of G-6-P; M, insulin-mediated glucose disposal rate; $R a$, appearance rate. 
Table I. Subject Characteristics

\begin{tabular}{|c|c|c|c|c|c|}
\hline $\begin{array}{l}\text { Subject } \\
\text { No. }\end{array}$ & Sex & Age & Weight & $\begin{array}{l}\text { Body } \\
\text { fat }\end{array}$ & $\begin{array}{l}\text { Fasting } \\
\text { plasma glucose }\end{array}$ \\
\hline & & $y r$ & $\mathrm{~kg}$ & $\%$ & $\mathrm{mg} / 100 \mathrm{ml}$ \\
\hline 1 & $\mathrm{~F}$ & 25 & 108.2 & 41 & 91 \\
\hline 2 & $\mathbf{M}$ & 22 & 134.8 & 41 & 91 \\
\hline 3 & $F$ & 20 & 63.4 & 34 & 93 \\
\hline 4 & $F$ & 18 & 135.7 & 49 & 96 \\
\hline 5 & $\mathbf{M}$ & 27 & 78.8 & 29 & 97 \\
\hline 6 & $\mathbf{M}$ & 28 & 76.3 & 21 & 97 \\
\hline 7 & $\mathbf{M}$ & 26 & 99.9 & 26 & 98 \\
\hline 8 & $\mathbf{M}$ & 18 & 85.3 & 25 & 98 \\
\hline 9 & $\mathbf{F}$ & 25 & 59.8 & 29 & 101 \\
\hline 10 & $\mathbf{F}$ & 20 & 109.1 & 45 & 104 \\
\hline 11 & $\mathbf{M}$ & 45 & 116.5 & 36 & 112 \\
\hline 12 & $\mathbf{F}$ & 20 & 90.6 & 36 & 113 \\
\hline 13 & $\mathbf{M}$ & 30 & 169.8 & 37 & 116 \\
\hline 14 & $\mathbf{F}$ & 22 & 92.6 & 34 & 118 \\
\hline 15 & $F$ & 22 & 104.9 & 40 & 137 \\
\hline 16 & F & 53 & 66.8 & 39 & 179 \\
\hline 17 & $\mathbf{M}$ & 34 & 110.1 & 33 & 188 \\
\hline 18 & $\mathbf{M}$ & 21 & 175.3 & 42 & 199 \\
\hline 19 & $\mathbf{F}$ & 33 & 93.2 & 35 & 209 \\
\hline 20 & $\mathbf{M}$ & 35 & 116.3 & 34 & 235 \\
\hline 21 & $\mathbf{M}$ & 38 & 88.0 & 33 & 252 \\
\hline 22 & $\mathbf{F}$ & 29 & 59.8 & 34 & 269 \\
\hline 23 & $\mathbf{F}$ & 33 & 102.5 & 43 & 275 \\
\hline 24 & $\mathbf{F}$ & 43 & 72.7 & 38 & 279 \\
\hline 25 & $\mathbf{F}$ & 43 & 75.7 & 36 & 310 \\
\hline
\end{tabular}

calcium, total protein, and albumin. No subjects were taking medications and all had a normal physical examination, electrocardiogram, and blood tests. After $3 \mathrm{~d}$ on a weight-maintaining diet containing at least $200 \mathrm{~g}$ of carbohydrate, an oral glucose tolerance test was performed (5). The percent body fat of each volunteer was estimated by underwater weighing with correction for the simultaneously measured residual lung volume (6).

Euglycemic clamp (See Fig. 1). After the oral glucose tolerance test and at $0500 \mathrm{~h}$ after a 10-h overnight fast, an intravenous catheter was

\section{$0 \quad 12345678910$ TIME (hours)}

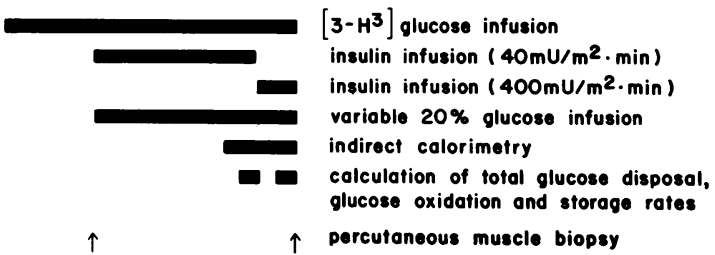

Figure 1. Schematic diagram of the hyperinsulinemic euglycemic clamp procedure with indirect calorimetry and percutaneous muscle biopsies. placed in an antecubital vein for infusion of insulin, glucose, and [3- $\mathrm{H}^{3}$ ]glucose. A primed $(30 \mu \mathrm{Ci})$-continuous $(0.30 \mu \mathrm{Ci} / \mathrm{min})$ infusion of $\left[3-\mathrm{H}^{3}\right]$ glucose was then begun and continued until the end of the study. Another catheter was placed retrograde in a dorsal vein of the contralateral hand for blood withdrawal. The hand was kept in a warming box at $70^{\circ} \mathrm{C}$. After $3 \mathrm{~h}$, a primed-continuous insulin infusion $(40 \mathrm{mU} /$ $\mathrm{m}^{2} \cdot \mathrm{min}$ ) was then started and continued for $340 \mathrm{~min}$. The mean plasma insulin concentration, determined on plasma samples drawn at 300 , $310,320,330$, and $340 \mathrm{~min}$ was $134 \pm 7 \mu \mathrm{U} / \mathrm{ml}$ (mean coefficient of variation $[\mathrm{C} . \mathrm{V}]=.5.0 \pm 1.0 \%$ ) for all subjects. Another primed-continuous insulin infusion $\left(400 \mathrm{mU} / \mathrm{m}^{2} \cdot \mathrm{min}\right)$ was then started and continued for $80 \mathrm{~min}$. This resulted in a mean plasma insulin concentration of $1709 \pm 72$ $\mu \mathrm{U} / \mathrm{ml}$ (mean C.V. $=10.0 \pm 1.0 \%$ ) on five blood samples drawn over the last $\mathbf{4 0} \mathrm{min}$ of this infusion. The lower plasma insulin concentration was considered to be within the physiologic range for this study population since the mean peak plasma insulin concentration during the oral glucose tolerance test was $295 \pm 49 \mu \mathrm{U} / \mathrm{ml}$. The higher plasma insulin concentration was considered to be a maximally stimulating insulin concentration $(7,8,9)$. After the start of the initial insulin infusion, a variable infusion of $20 \%$ glucose was given as necessary to maintain the plasma glucose concentration at $\sim 100 \mathrm{mg} / 100 \mathrm{ml}$ for all subjects. Thus, in the hyperglycemic subjects, the glucose infusion was not begun until the plasma glucose concentration had declined to $100 \mathrm{mg} / 100 \mathrm{ml}$. Blood for plasma glucose concentration was drawn every $5 \mathrm{~min}$ throughout the test. The mean plasma glucose concentration for all subjects was $102 \pm 0.5 \mathrm{mg} / 100 \mathrm{ml}$ (mean C.V. $=2.0 \pm 0.1 \%$ ) during the last $40 \mathrm{~min}$ of the low-dose insulin infusion, and was $101 \pm 0.5 \mathrm{mg} / 100 \mathrm{ml}$ (mean C.V. $=3.0 \pm 0.1 \%$ ) during the last $40 \mathrm{~min}$ of the high-dose insulin infusion. Blood for plasma [3- $\mathrm{H}^{3}$ ]glucose specific activity was drawn every 10 min from 300-340 and from 380-420 min to determine the [3- $\left.\mathrm{H}^{3}\right]$ glucose specific activity for calculation of the glucose appearance rate (see below).

Indirect calorimetry. Beginning $1 \mathrm{~h}$ before the end of the low-dose insulin infusion (Fig. 1), a clear, plastic, ventilated hood was placed over the subject's head. Room air was drawn through the hood and the flow rate measured by a pneumotachograph (Gould, Cleveland, $\mathrm{OH}$ ). A constant fraction of expired air was withdrawn and analyzed for oxygen and carbon dioxide content. The oxygen analyzer was a zirconium cell analyzer (Applied Electrochemistry, Sunnyvale, CA) and the carbon dioxide analyzer was an infrared analyzer (Applied Electrochemistry). The analyzers and flowmeter were connected to a desktop computer (Hewlett-Packard, Palo Alto, CA). This recorded continuous, integrated calorimetric measurements every $5 \mathrm{~min}$ from 280 to $420 \mathrm{~min}$ after the start of the insulin infusion. The protein oxidation during the test was estimated from the urinary urea production rate. The nonprotein respiratory quotient was then calculated and the substrate oxidation rates determined from the equations of Lusk (10).

Muscle biopsy, glycogen synthase, and glycogen content determination. $3 \mathrm{~h}$ after the start of the [3- $\left.\mathrm{H}^{3}\right]$ glucose infusion, and just prior to starting the insulin infusion (Fig. 1), a percutaneous biopsy of the vastus lateralis muscle was performed. The specimen was immediately frozen in liquid nitrogen, stored at $-70^{\circ} \mathrm{C}$, and later, assayed for glycogen content and glycogen synthase activity. The muscle biopsy was repeated at the end of the insulin infusion. The method of Nuttall et al. (11) was modified for homogenization of muscle biopsies. Aliquots of the homogenate were stored at $-20^{\circ} \mathrm{C}$ for the determination of glycogen content. The remaining homogenate was centrifuged at $8,000 \mathrm{~g}$ for $10 \mathrm{~min}$ and aliquots of the supernatant were stored at $-20^{\circ} \mathrm{C}$ for protein assay or used immediately for determination of glycogen synthase activity. Previously, we (4) and others (12) have reported glycogen synthase activity as the "\%I activity" or the percent of active enzyme in the absence of G-6-P. 
To more closely match in vivo conditions, we now have measured glycogen synthase activity at a low G-6-P concentration $(0.17 \mathrm{mM})$ in the presence of $0.14 \mathrm{mM}$ UDP glucose (13). Maximal activity was measured at high G-6-P $(7.2 \mathrm{mM})$ and in the presence of $0.14 \mathrm{mM}$ UDP glucose. Activity was measured by using UDP $\left[{ }^{14} \mathrm{C}\right]$ glucose and is expressed as nanomoles of glucose incorporated into glycogen per minute per milligram of protein. Frozen aliquots for glycogen determination were thawed and assayed according to the method of Hultman et al. (14).

Aliquots of the supernatant were diluted threefold with $50 \mathrm{mM}$ potassium fluoride $60 \mathrm{mM} 2$-mercaptoethanol, $50 \mathrm{mM} 2$-( $N$-morpholine)

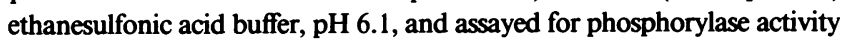
according to the modified assay reported by Tan et al. (15) omitting AMP in the substrate for phosphorylase $a$. This assay is based on the incorporation of [U-C $\left.{ }^{14}\right]$ Glucose-1-P into glycogen (16) with units of activity calculated as the nanomoles of glucose incorporated into glycogen per minute per milligram of protein.

Calculations and analyses. The appearance rate ( $\mathrm{Ra})$ of glucose in the plasma was calculated from the blood [3- $\left.\mathrm{H}^{3}\right]$ glucose specific activities by using Steele's non-steady state equations (17). The total glucose disposal rate (M) is equal to the $\mathrm{Ra}$. When the isotopically determined $\mathrm{Ra}$ was equal to the exogenous glucose infusion rate, the endogenous glucose production was assumed to be fully suppressed, and then, $M$ equals the exogenous glucose infusion rate. These data were calculated for each 20-min period between $300-340$ and 380-400 min, or during the last $40 \mathrm{~min}$ of the low- and high-dose insulin infusions, and then averaged to calculate the mean total glucose disposal rate during this period of both insulin infusions. The insulin-stimulated carbohydrate oxidation rates were calculated from the indirect calorimetric data by also averaging the data for the last $\mathbf{4 0}$ min during the low- and high-dose insulin infusion. The carbohydrate storage rate was estimated by subtracting the carbohydrate oxidation rate from the total glucose disposal rate, during both insulin infusions. Plasma insulin concentrations were determined by radioimmunoassay, and tritiated glucose specific activity in blood samples was determined after precipitating protein with perchloric acid as described by others (18).

Statistics. All data are expressed as the mean \pm SEM. All statistical analyses were calculated using Statistical Analysis System, SAS Institute, Inc., Cary, NC. Simple correlations are Pearson product-moment correlations.

\section{Results}

Muscle glycogen content and glycogen synthase activity, measured at a low G-6-P $(0.17 \mathrm{mM})$ concentration (GSLo) before and after the euglycemic clamp, are listed in Table II. Muscle glycogen content ranged from 83 to $258 \mathrm{mg} / \mathrm{g}$ protein and increased in 18 subjects following the euglycemic clamp. Muscle GSLo ranged from 1.5 to $3.9 \mathrm{nmol} / \mathrm{min} \cdot \mathrm{mg}$ protein prior to the insulin infusion and increased in 21 of the 25 subjects following the euglycemic clamp. The change in muscle GSLo in response to the insulin and glucose infusion was significantly correlated with the change in muscle glycogen content $(r=0.46$, $P<0.03$ ) (Fig. 2).

Although the correlation was significant, it was a weaker relationship than might be predicted if glycogen synthesis rates are accurately reflected by glycogen synthase activity. This sug-
Table II. Muscle Glycogen Content and Muscle Glycogen Synthase Activity Before and After the Euglycemic Clamp Procedure

\begin{tabular}{|c|c|c|c|c|}
\hline \multirow[b]{2}{*}{ Subject } & \multicolumn{2}{|c|}{$\begin{array}{l}\text { Muscle glycogen content } \\
\text { (mg/g protein) }\end{array}$} & \multicolumn{2}{|c|}{$\begin{array}{c}\text { Muscle glycogen synthase } \\
\text { activity* (nmol/min. } \\
\text { mg protein) }\end{array}$} \\
\hline & $\begin{array}{l}\text { Before } \\
\text { "clamp" }\end{array}$ & $\begin{array}{l}\text { After } \\
\text { "clamp" }\end{array}$ & $\begin{array}{l}\text { Before } \\
\text { "clamp" }\end{array}$ & $\begin{array}{l}\text { After } \\
\text { "clamp" }\end{array}$ \\
\hline 1 & 136 & 201 & 3.7 & 7.1 \\
\hline 2 & 189 & 223 & 1.9 & 3.9 \\
\hline 3 & 199 & 191 & 2.7 & 5.2 \\
\hline 4 & 141 & 224 & 2.7 & 7.0 \\
\hline 5 & 182 & 197 & 1.7 & 5.8 \\
\hline 6 & 201 & 267 & 1.6 & 4.0 \\
\hline 7 & 175 & 220 & 3.9 & 7.9 \\
\hline 8 & 185 & 226 & 3.3 & 8.2 \\
\hline 9 & 137 & 96 & 1.5 & 4.0 \\
\hline 10 & 258 & 223 & 3.2 & 3.4 \\
\hline 11 & 146 & 214 & 2.8 & 5.4 \\
\hline 12 & 179 & 161 & 2.1 & 3.6 \\
\hline 13 & 119 & 152 & 2.0 & 4.1 \\
\hline 14 & 165 & 128 & 2.2 & 2.0 \\
\hline 15 & 83 & 110 & 2.1 & 3.2 \\
\hline 16 & 182 & 191 & 2.8 & 2.5 \\
\hline 17 & 112 & 145 & 2.2 & 5.6 \\
\hline 18 & 186 & 202 & 2.1 & 1.5 \\
\hline 19 & 106 & 97 & 2.1 & 2.2 \\
\hline 20 & 92 & 212 & 1.8 & 4.2 \\
\hline 21 & 184 & 184 & 1.8 & 3.3 \\
\hline 22 & 166 & 178 & 2.1 & 2.2 \\
\hline 23 & 204 & 205 & 3.9 & 4.3 \\
\hline 24 & 256 & 296 & 3.3 & 3.7 \\
\hline 25 & 168 & 198 & 2.2 & 1.5 \\
\hline
\end{tabular}

* Muscle glycogen synthase activity was measured in the presence of $0.17 \mathrm{mM} \mathrm{G-6-P}$ and $0.14 \mathrm{mM}$ UDP glucose.

gested that glycogenolysis may have increased during the euglycemic clamp procedure. Therefore, on the remaining muscle tissue from our study subjects, we measured phosphorylase $a$ activity before and after the insulin infusions. The results were only available on six subjects because of the small amount of muscle tissue remaining for analysis. In four of these subjects, there was an increase in phosphorylase $a$ activity (Nos. 1, 11, 20 , and 23), in one (No. 21) there was no change, and in one (No. 6) subject a small decrease.

The mean maximal glycogen synthase activity did not change significantly $(6.8 \pm 0.5$ to $7.5 \pm 0.4 \mathrm{nmol} / \mathrm{min} \cdot \mathrm{mg}$ protein $)$ following the insulin infusions. The muscle glycogen synthase activity measured at a low G-6-P concentration relative to the activity in the presence of high G-6-P (\%GSLo), a term which estimates the level of activity of the enzyme in vivo, ranged from 37 to $56 \%$. The change in muscle \%GSLo, was significantly 


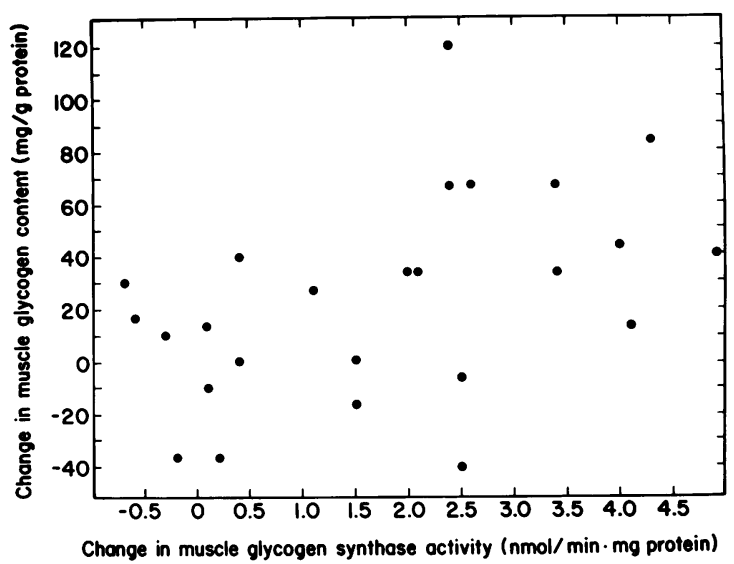

Figure 2. Relationship between the change in muscle glycogen synthase activity and the change in muscle glycogen content following the euglycemic clamp procedure. Muscle glycogen synthase activity was determined in the presence of $0.17 \mathrm{mM} \mathrm{G-6-P}$ and $0.14 \mathrm{mM}$ UDP glucose. $r=0.46, P<0.03$.

correlated with the change in muscle GSLo $(r=0.78, P<0.001)$. The relationships between \%GSLo or GSLo and in vivo insulin action were similar (vide infra). However, \%GSLo is a relative term and does not indicate the units of enzyme activity present in the muscle. Therefore, we have reported the data as GSLo (activity in the presence of $0.17 \mathrm{mM}$ G-6-P and $0.14 \mathrm{mM}$ UDP glucose). This is a quantitative assessment, in vitro, of the ability of the muscle enzyme to convert glucose to glycogen.

The insulin-mediated glucose disposal (M) and storage rates are expressed as milligrams per kilogram of fat-free mass per minute. As can be seen in Fig. 3, insulin-mediated glucose storage rates were distributed over a broad range during both the low $(-0.11-2.42 \mathrm{mg} / \mathrm{kg}$-fat-free mass [ffm] $\cdot \mathrm{min})$ and high $(-0.22-$ $9.95 \mathrm{mg} / \mathrm{kg}-\mathrm{ffm} \cdot \mathrm{min}$ ) dose insulin infusions as were the $M$ values $(1.79-6.10 \mathrm{mg} / \mathrm{kg}-\mathrm{ffm} \cdot \mathrm{min}$ and 3.21 to $15.91 \mathrm{mg} / \mathrm{kg}-\mathrm{ffm} \cdot \mathrm{min})$. $M$ values were well correlated with insulin-mediated glucose storage rates during the low $(r=0.82, P<0.0001)$ and high ( $r=0.97, P<0.0001)$ dose insulin infusions, respectively.

There was a significant correlation between the muscle GSLo at the end of the insulin infusions and glucose storage rates measured during the low $(r=0.50, P<0.02)$ (Fig. $3 A)$ and high $(r=0.78, P<0.0001)$ dose insulin infusions (Fig. $3 \mathrm{~B}$ ). Similarly, the change in GSLo (after insulin infusion minus before insulin infusion) also correlated with the glucose storage rates during the insulin infusions $(r=0.59, P<0.01$ and $r$ $=0.74, P<0.0001$ ). Muscle GSLo at the end of the euglycemic clamp also correlated with $M$ during the low $(r=0.66, P<0.001)$ and high $(0.76, P<0.0001)$ dose insulin infusion. Similarly, the change in GSLo also correlated with $M$ during the insulin infusions $(r=0.68, P<0.001$ and $r=0.70, P<0.001)$. Muscle glycogen content, before or after the euglycemic clamp, and the change in muscle glycogen content following the insulin infusion did not correlate significantly with $\mathbf{M}$ or glucose storage rates.

\section{Discussion}

Previous studies in man have shown that glucose given orally or intravenously is taken up predominantly by muscle $(1,2)$. In addition, DeFronzo et al. (1) reported that insulin-mediated glucose disposal into muscle was primarily by nonoxidative pathways, presumably glycogen synthesis. These data suggested, therefore, that reductions in insulin-mediated glucose disposal rates observed in man might be secondary to abnormalities of glycogen synthesis. In addition, since glycogen synthase is known to be the rate-controlling enzyme for muscle glycogen synthesis (3), we hypothesized that decreased glycogen synthase activity may be related to decreased insulin action in vivo in man. Our results show that there is a good correlation between muscle glycogen synthase activity and in vivo insulin-mediated glucose storage rates as well as net glucose disposal rates in glucosetolerant and diabetic subjects. The correlation coefficients between these parameters were higher at supraphysiologic insulin concentrations probably because the muscle biopsies were done after the high-dose insulin infusion and not directly after the low-dose insulin infusion. Nonetheless, muscle glycogen synthase
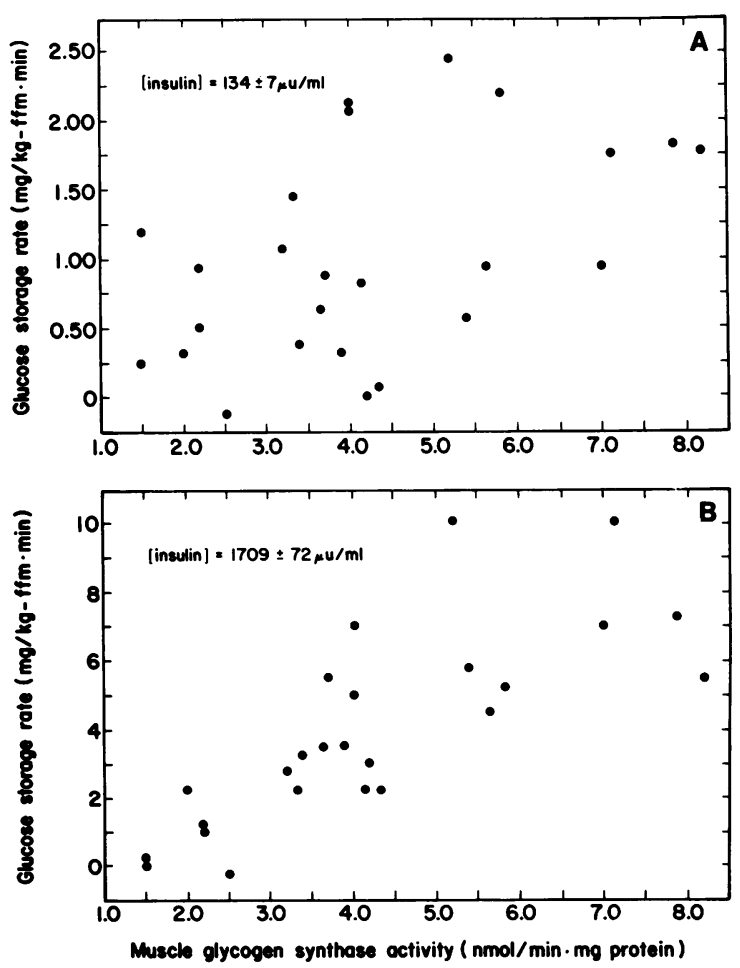

Figure 3. Relationship between the glucose storage rates and muscle glycogen synthase activity measured at the end of the insulin infusions; at a mean plasma insulin concentration of $(A) 134 \pm 7 \mu \mathrm{U} / \mathrm{ml}(r$ $=0.50, P<0.02)$ and $(B) 1709 \pm 72 \mu \mathrm{U} / \mathrm{ml}(r=0.78, P<0.0001)$. Muscle glycogen synthase activity was determined in the presence of $0.17 \mathrm{mM}$ G-6-P and $0.14 \mathrm{mM}$ UDP glucose. 
activity was well correlated with glucose storage and net disposal rates measured during the low-dose insulin infusions, suggesting that the observed relationships have physiologic relevance.

We have previously reported (4) a good correlation between glycogen synthase \%I activity and in vivo insulin action in lean Caucasian males following glycogen-depleting exercise. Those data and our present results suggest that glycogen synthase activation, either by glycogen depletion or by insulin, is well correlated with insulin-mediated glucose disposal rates. Thus, at rest or after exercise, glycogen synthase activity appears to be a determinant of in vivo insulin action in man. Our results agree with the data in the abstract of Evans et al. (12) who reported a good correlation between the increment in glycogen synthase \% I activity and in vivo insulin resistance, as measured by the steady state plasma glucose technique in obese, nondiabetic females. They concluded that decreased insulin responsiveness during the steady state plasma glucose procedure was due to a decrease in insulin receptor number. We cannot determine from our data whether the relationships observed between in vivo insulin action and muscle glycogen synthase activity are due to changes in insulin receptor number or affinity, or postreceptor events. Our results also agree with a recent report by Goldstein et al. (19) showing an impaired glycogen synthase activation system in diabetic human polymorphonuclear leukocytes. The present data suggest that their findings in leukocytes may parallel changes in glycogen synthase activation in muscle tissue.

There was a weak, but significant correlation between the change in muscle glycogen content and the change in glycogen synthase activity in response to the insulin infusions in this study $(r=0.46, P<0.03$ ). This suggests that muscle glycogen synthase activity does indeed reflect the capability of the subjects to synthesize glycogen in response to insulin. However, in seven subjects, there was no measured increase in muscle glycogen content. Three of these subjects (Nos. 10, 14, and 19) had little or no increase in glycogen synthase activity during the insulin and glucose infusions, and therefore, would be expected to have very little change in muscle glycogen content. When the small amount of glucose infused in these subjects is distributed over the entire muscle mass of the body, the actual change in muscle glycogen concentration would be so small as to be undetectable by current methods. In four of these seven subjects (Nos. 3, 9, 12 , and 21), a measurable increase in muscle glycogen content would have been expected from the measured glycogen synthase activation and glucose storage rates. There was no apparent technical explanation for the unusual glycogen results in these subjects so their results were included. Despite these three subjects, there was still a significant correlation between the change in glycogen synthase activity and glycogen content during the euglycemic clamp procedure. Muscle glycogen concentration is a result of both rates of glycogen synthesis and glycogenolysis. It is quite possible that newly synthesized glycogen is metabolized during the euglycemic clamp procedure as observed in rats following oral glucose (20). The increased phosphorylase $a$ activity in the muscle tissue in four of six subjects in this study provides preliminary evidence in man that glycogenolysis increases in some subjects during the euglycemic clamp procedure. Muscle glycogen synthase activity only estimates glycogen synthesis rates and not rates of glycogenolysis. A higher correlation between glycogen synthase activation and change in muscle glycogen content might occur if glycogenolysis was absent during the insulin infusion. In vivo rates of glycogenolysis will need to be more thoroughly assessed during insulin infusions to properly interpret the relationship between the change in muscle glycogen content and in vivo insulin action. However, this does not detract from the importance of the relationship between glycogen synthase activity and in vivo insulin action. Glycogen synthase activity estimates glycogen synthesis rates, and the good correlation with insulin-mediated glucose disposal rates observed in this study emphasizes the possible importance of glycogen synthesis in muscle in determining in vivo insulin-mediated glucose disposal rates in man. However, establishing a direct cause and effect relationship between muscle glycogen synthase activity and in vivo insulin-mediated glucose disposal rates will require further study.

\section{Acknowledgments}

We thank the nursing staff for their professional care of the subjects while on the research ward and for their assistance in performing the many procedures. We thank Verna Kuwanhoyioma for her secretarial assistance, and most of all, we thank the volunteers.

\section{References}

1. DeFronzo, R. A., E. Jacot, E. Jequier, E. Maeder, J. Wahren, and J. P. Felber. 1981. The effect of insulin on the disposal of intravenous glucose. Results from indirect calorimetry and hepatic and femoral venous catheterization. Diabetes. 30:1000-1007.

2. Katz, L. D., M. G. Glickman, S. Rapoport, E. Ferrannini, and R. A. DeFronzo. 1983. Splanchnic and peripheral disposal of oral glucose in man. Diabetes. 32:675-679.

3. Leloir, L. F., J. M. Olavarria, S. H. Goldemberg, and H. Carminatti. 1959. Biosynthesis of glycogen from uridine diphosphate glucose. Arch. Biochem. Biophys. 81:508-520.

4. Bogardus, C., P. Thuillez, E. Ravussin, M. Narigma, and S. Azhar. 1983. Effect of muscle glycogen depletion on in vivo insulin action in man. J. Clin. Invest. 72:1605-1610.

5. National Diabetes Data Group. 1979. Classification and diagnosis of diabetes mellitus and other categories of glucose intolerance. Diabetes. 28:1039-1057.

6. Goldman, R. F., and E. R. Buskirk. 1961. A method for underwater weighing and the determination of body density. In Techniques for Measuring Body Composition. J. Brozek, and A. Herschel, editors. National Academy of Sciences, National Research Council, Wash., DC. 78-89.

7. Kolterman, O. G., J. Insel, M. Saekow, and J. M. Olefsky. 1980. Mechanisms of insulin resistance in human obesity. Evidence for receptor and postreceptor defects. J. Clin. Invest. 65:1272-1284.

8. DeFronzo, R. A. 1982. Insulin secretion, insulin resistance, and obesity. Int. J. Obesity. 6(Suppl. 1):73-82.

9. Rizza, R. H., L. J. Mandarino, and J. E. Gerich. 1981. Dose- 
response characteristics for effects of insulin on production and utilization of glucose in man. Am. J. Physiol. 240:E630-E639.

10. Lusk, G. 1924. Animal calorimetry. Analysis of oxidation of mixtures of carbohydrate and fat. J. Biol. Chem. 59:41-42.

11. Nuttall, F. Q., J. Barbosa, and M. C. Cannon. 1974. The glycogen synthase system in skeletal muscle of normal humans and patients with myotonic dystrophy. Effect of glucose and insulin administration. Metab. Clin. Exp. 23:561-568.

12. Evans, D. J., R. Kulkhoff, and A. H. Kissebah. 1982. Skeletal muscle insulin resistance in human obesity. Clin. Res. 30:391A.

13. Guinovart, J. J., A. Salavert, J. Massague, C. J. Ciudad, E. Salsas, and E. Itarte. 1979. Glycogen synthase: a new activity ratio assay expressing a high sensitivity to the phosphorylation state. FEBS (Fed. Eur. Biochem. Soc.) Lett. 106:284-288.

14. Hultman, E. 1967. Muscle glycogen in man determined in needle biopsy specimens. Method and normal values. Scand. J. Clin. Lab. Invest. 19(Suppl. 91):1-63.

15. Tan, A. W. H., and F. Q. Nuttall. 1975. Characteristics of the dephosphorylated form of phosphorylase purified from rat liver and measurement of its activity in crude liver preparations. Biochim. Biophys. Acta. 410:45-60.

16. Gilboe, D. P., K. L. Larson, and F. Q. Nuttall. 1972. Radioactive method for the assay glycogen phosphorylases. Anal. Biochem. 47:2027.

17. Steele, R. 1959. Influences of glucose loading and of injected insulin on hepatic glucose output. Ann. NY Acad. Sci. 82:420-430.

18. Best, J. D., R. G. Judzewitsch, M. A. Pfeifer, J. C. Beard, J. B. Halter, and D. Porte, Jr. 1982. The effect of chronic sulfonylurea therapy in hepatic glucose production in non-insulin dependent diabetes. $\mathrm{Di}$ abetes. 31:333-338.

19. Goldstein, D. E., and R. T. Curnow. 1980. Impaired glycogen synthase activating system in human diabetic polymorphonuclear leukocytes. Diabetes. 29:217-220.

20. Nuttal, F. Q., M. C. Gannon, and J. Larner. 1972. Oral glucose effect on glycogen synthetase and phosphorylase in heart, muscle and liver. Physiol. Chem. Phys. 4:497-515. 